\title{
Characterisation of the shortwave radiation regime for locations at different altitudes in south-west Germany
}

\author{
M. G. Iziomon*, H. Mayer \\ Meteorological Institute, University of Freiburg, Werderring 10, 79085 Freiburg, Germany
}

\begin{abstract}
The shortwave radiation regime for 3 REKLIP sites at different altitudes in south-west Germany has been characterised. The study period extended from 1992 to 1995. Climatic variables used for the characterisation include surface albedo, cloud cover, relative sunshine duration, fog frequency, atmospheric clearness index and precipitation. Given clear sky conditions, the atmospheric clearness index amounted to $76 \%$ at the upper mountain site (1489 m above sea level [a.s.l.]) and $68.5 \%$ at the lowland site $(212 \mathrm{~m}$ a.s.l.). Although the vertical profile of incoming solar radiation exhibited a positive gradient on clear sky days (independent of season), the net shortwave radiation showed a dissimilar trend in winter, when albedo values were significantly high at the mountain sites. In general, net shortwave radiation at the lowland site was 1.1 and 1.2 times that of the intermediate and upper mountain sites respectively. For each season, theoretically computed diffuse sky radiation increased with cloud cover, $N$, only to a maximum of about 5 octa, while the diffuse fraction, $K_{\mathrm{d}}$, of solar radiation rose steadily with $N$. From April to October, the estimated monthly $K_{\mathrm{d}}$ increased with altitude, being vice-versa for the other months.
\end{abstract}

KEY WORDS: Solar radiation - Net shortwave radiation $\cdot$ Atmospheric clearness index $\cdot$ Diffuse fraction $\cdot$ Albedo $\cdot$ Relative sunshine duration $\cdot$ Cloud cover $\cdot$ REKLIP

\section{INTRODUCTION}

Incoming solar radiation, $G$, is crucial to climatic processes at the surface, as it plays a major role in the energy exchange between land-ocean surface and the atmosphere. Consequently, surface radiation data constitutes a valuable resource for validating satellite retrieval algorithms as well as general circulation models (Garratt 1994, Wild et al. 1995, Friis-Christensen 2000). Moreover, the design of solar energy conversion systems requires adequate knowledge of the shortwave radiation regime (Hammonds 2000, Ianetz et al. 2000).

The diffuse sky radiation, $D$, is a significant constituent of the shortwave radiation regime, especially

${ }^{*}$ Present address: Department of Physics and Atmospheric Science, Dalhousie University, Halifax, Canada.

E-mail: iziomon@mathstat.dal.ca in hazy and cloudy sky conditions, when the variability of $G$ is almost entirely governed by $D$. In addition, the knowledge of $D$ is required in a number of applications, including solar power installations, air conditioning of buildings, atmospheric turbidity studies, ecology and solar irradiance receptivity of solar collectors (Iziomon \& Aro 1998).

In spite of the profound information that can be derived from the long-term measurements of shortwave radiation fluxes over diverse terrains, the technicality and rising costs of running and maintaining standardised radiometric stations is leading to a dearth of insolation data at many locations in the world (Thornton \& Running 1999, Liu \& Scott 2001). Furthermore, most of the existing radiation measurement networks are of uneven density and of large spatial scale, covering mainly valley and lowland areas, so that most of the available information is inevitably biased towards 
lower elevations (Barry 1992, Thornton et al. 2000). Thus, in current practice, the extrapolation of data from a nearby station as well as interpolation in networks or satellite-based methods are considered as alternatives to ground-based measurements. There are, however, constraints with respect to heterogeneous regions.

The Upper Rhine Valley region (which extends from Karlsruhe [Germany] in the north, to Basel [Switzerland] in the south, and from the Vosges [France] in the west to the Black Forest [Germany] in the east) exhibits a significantly inhomogeneous terrain, with a pronounced temporal and spatial variability of climatic variables (Kalthoff et al. 1999). In an attempt to investigate climatic conditions and energy-balance components within the entire upper Rhine Valley region, REKLIP (Regio-Klima-Projekt) set up a network of 36 stations in 1989 (although measurements commenced at most of the sites in 1991). An overview of the climate in the Upper Rhine Valley region is presented in REKLIP (1995). Kalthoff et al. (1999) presented energy-balance components for the region as a function of land use, precipitation and orography.

Since a large percentage of REKLIP stations lie in the upper Rhine lowland area, the possibility for a study on the vertical profile of radiative fluxes is rather low. In view of this, this paper will focus on 3 grassland sites (located within a relatively small area in the southern part of the REKLIP area) whose elevation ranges from 212 to $1489 \mathrm{~m}$ above sea level (a.s.l.). The shortwave radiation regime at these sites will be investigated based on sky conditions, atmospheric clearness index, relative sunshine duration, altitude, fog frequency and surface albedo. In addition, since $D$ was not measured during REKLIP, no study has so far been undertaken to investigate it in the study area. In general, it is difficult to monitor the impact of changes in cloud cover and aerosol content on $D$ within the REKLIP area. Consequently, another goal of this study is to estimate $D$ and examine its characteristics at low- and high-altitude locations.

\section{EXPERIMENTAL SITES AND DATABASE}

The study sites are located in south-west Germany: at Bremgarten ( $47^{\circ} 54^{\prime} 35^{\prime \prime} \mathrm{N}, 7^{\circ} 37^{\prime} 18^{\prime \prime} \mathrm{E}, 212 \mathrm{~m}$ a.s.l.) within the Upper Rhine lowland area, Geiersnest $\left(47^{\circ} 55^{\prime} 03^{\prime \prime} \mathrm{N}, 7^{\circ} 51^{\prime} 16^{\prime \prime} \mathrm{E}, 870 \mathrm{~m}\right.$ a.s.l.) on the outskirts of the Black Forest, and Feldberg $\left(47^{\circ} 52^{\prime} 31^{\prime \prime} \mathrm{N}\right.$, $8^{\circ} 00^{\prime} 11^{\prime \prime} \mathrm{E}, 1489 \mathrm{~m}$ a.s.l.) at the summit of the Black Forest (Iziomon 2000). Bremgarten (Br) lies about $20 \mathrm{~km}$ south-west of Geiersnest (Ge) while Feldberg (Fe) is approximately $13 \mathrm{~km}$ south-east of Geiersnest. In view of their elevations and for easy reference, these study sites will be alternatively referred to as the lowland site (Bremgarten), the intermediate mountain site (Geiersnest) and the upper mountain site (Feldberg).

Global solar radiation was measured by a horizontally positioned upward-facing CM11 pyranometer (Kipp \& Zonen, Delft, The Netherlands) installed at $2 \mathrm{~m}$ above the ground. The reflected shortwave component, $R_{\mathrm{s} \text {, was }}$ measured using another horizontally positioned downward-facing CM11 pyranometer installed at $1.9 \mathrm{~m}$ above the ground. The accuracy of the radiometers was rated to be better than $5 \%$ during daytime conditions. Net (or absorbed) shortwave radiation, $R_{\mathrm{ns}}$, was obtained from:

$$
R_{\mathrm{ns}}=G(1-a)
$$

where $a=R_{\mathrm{s}} / G$ denotes the surface albedo. Moreover, air temperature, $T_{\mathrm{a}}$, and humidity were measured using a wet and dry bulb psychrometer system installed at $2 \mathrm{~m}$ above the surface. The present study is based on measurements taken from January 1992 to December 1995 at the 3 sites. However it is worth mentioning that the data set for 1994 at Feldberg was only available for the second half of the year (due to storm-induced collapse of the measuring mast and the consequent lack of data from January to June 1994 for this mountain site).

In addition, hourly data on cloud cover for Feldberg (January 1991-October 1994) and data on sunshine duration for Feldberg (January 1991-October 1994) and Bremgarten (January 1991-February 1995) were provided by the German Weather Service. Hourly cloud cover data for Bremgarten extending from January 1991 to February 1993 was obtained from German Geophysical Consultant Services.

From the point of view of climatic characteristics, the study sites lie in the transition area from maritime to continental climate, thus possessing a relatively mild and moderately humid climate. Table 1 presents a summary of annual mean and standard deviation of air temperature, vapour pressure, relative humidity, wind speed and precipitation at the study sites from 1992 to 1995. A more elaborate description of the topography and weather conditions at the study sites is presented in Iziomon (2000). 

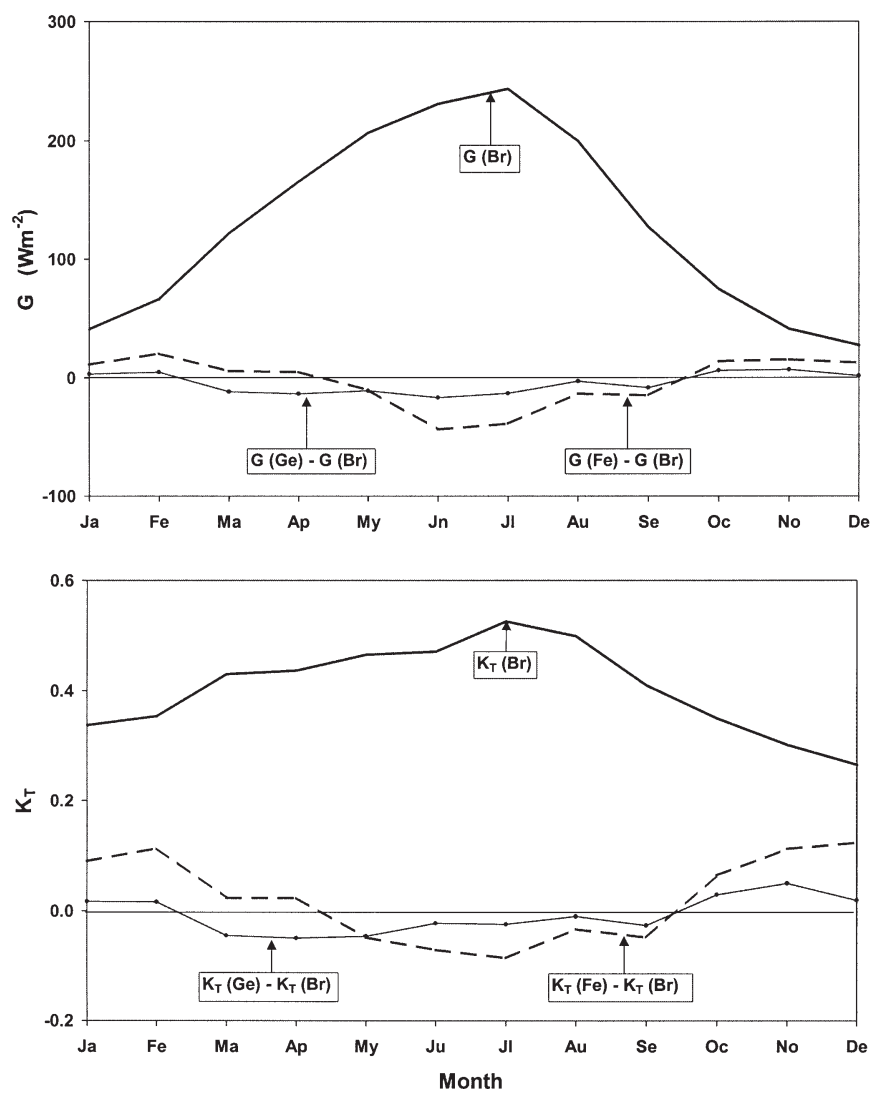

Fig. 1. Monthly mean of incoming solar radiation, $G$, and atmospheric clearness index, $K_{\mathrm{T}}$, at the lowland site (Br) as well as the inter-site difference in these variables relative to the lowland site

\section{RESULTS AND DISCUSSION}

\subsection{Annual variation of incoming solar radiation at the study sites}

Fig. 1 presents monthly means of $G$ and atmospheric clearness index, $K_{\mathrm{T}}$ (ratio of solar radiation to extraterrestrial radiation), at the lowland site, as well as the intersite differences in these variables relative to the lowland site. At all the study sites, the highest monthly mean of $G$ was recorded in July (essentially due to long daylength and high solar altitude) and the lowest in December. However, the magnitude of monthly values of $G$ at the lowland site differs considerably from that at the intermediate and upper mountain sites.

As implied in Fig. 1, monthly mean values of $G$ decreased with altitude from May to September. During this period, $G$ ranged from 127.3 to $243.7 \mathrm{~W} \mathrm{~m}^{-2}$ at the lowland site, from 119.1 to $230.7 \mathrm{~W} \mathrm{~m}^{-2}$ at the intermediate mountain site and from 112.6 to $205.0 \mathrm{~W} \mathrm{~m}^{-2}$ at the upper mountain site. Correspondingly, $K_{\mathrm{T}}$ varied from 0.41 to 0.53 at the lowland site, from 0.38 to 0.50 at the intermediate mountain site and from 0.36 to 0.47 at the upper mountain site. In addition to $K_{\mathrm{T}}$, lower values of $G$ recorded at the mountain sites for these months is also consistent with observed high cloud cover, $N$, and low relative sunshine duration, $S / S_{0}$ (where $S$ is the measured sunshine duration and $S_{0}$ is the computed daylength), at the sites. While $N$ at the upper mountain site ranged between 53 and $70 \%$ from May to September (Fig. 2), $N$ at the lowland site showed a smaller range (42 to $64 \%$ ). In contrast to $N$, $S / S_{0}$ (during this period) varied between 33.7 and $44.1 \%$ at the upper mountain site but between 42.9 and $62.6 \%$ at the lowland site (Fig. 2).

From October to March, $G$ ranged from 40.2 to $127.8 \mathrm{~W} \mathrm{~m}^{-2}$ at the upper mountain site, but varied between 27.5 and $122 \mathrm{~W} \mathrm{~m}^{-2}$ at the lowland site (with $K_{\mathrm{T}}$ ranging from 0.39 to 0.46 at the former and from 0.26 to 0.44 at the latter). Lower $G$ recorded in autumn and winter months at the lowland site can likely be attributed to the effect of fog (with its associated poor visibility) and stratus clouds (as evidenced by the large amount of cloud at the lowland site during this period; Fig. 2). Hourly fog frequency at the lowland site amounted to $58.6 \%$ in winter, $2.4 \%$ in spring, $1.2 \%$ in summer and $37.8 \%$ in autumn.
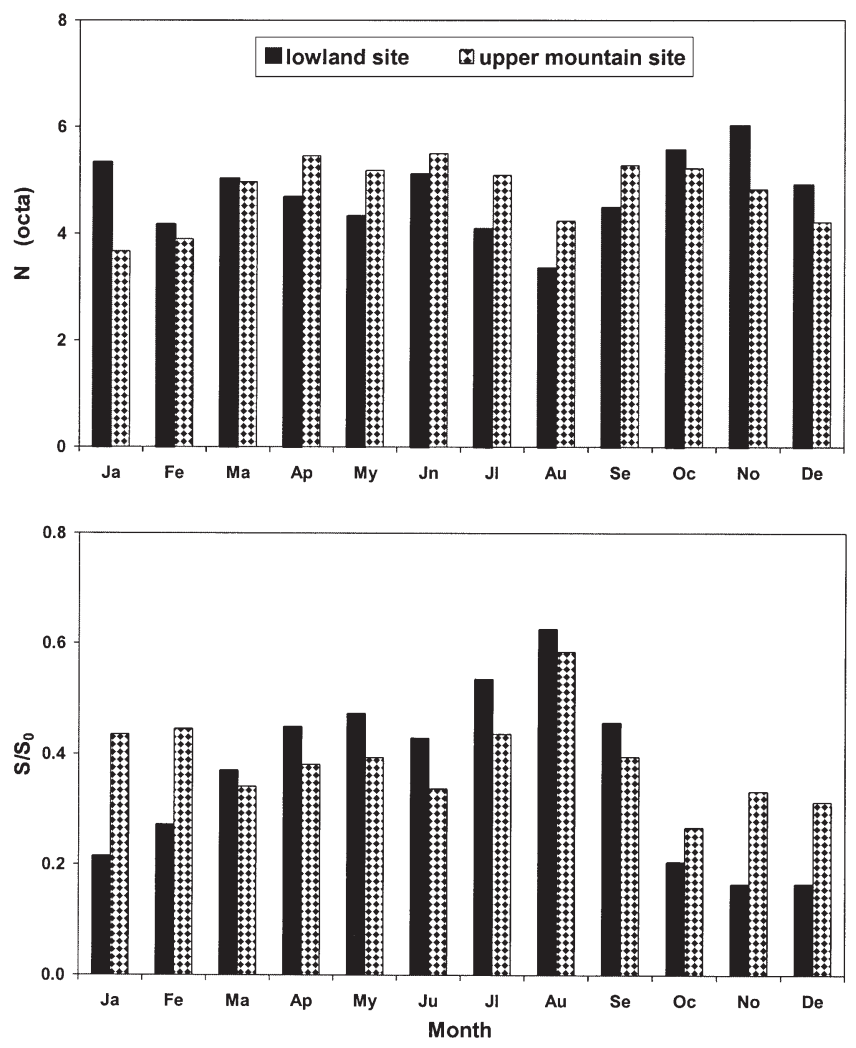

Fig. 2. Monthly mean of cloud cover, $N$, and relative sunshine duration $S / S_{0}$, at the lowland and upper mountain sites 
Higher monthly $G$ at the upper mountain site (relative to the lowland site) from late autumn to winter is also consistent with higher $S / S_{0}$ at this site, which ranged from 0.27 to 0.45 as compared to the lowland site. In general, the daily sum of $G\left(\mathrm{MJ} \mathrm{m}^{-2} \mathrm{~d}^{-1}\right)$ in the study area can be approximated by:

$$
\begin{gathered}
\sum_{\tau=S r}^{S S} G=\left(X+Y \bar{N}-Z \bar{N}^{2}\right) \sum_{\tau=S r}^{S S} E_{0} \\
\sum_{\tau=S r}^{S S} G=\left(\alpha+\frac{\beta S}{S_{0}}\right) \sum_{\tau=S r}^{S S} E_{0}
\end{gathered}
$$

where $E_{0}\left(\mathrm{MJ} \mathrm{m}^{-2} \mathrm{~d}^{-1}\right)$ is the extraterrestrial radiation, $\tau$, sr and ss denote time, sunrise and sunset respectively, and $\bar{N}$ represents the daily mean of cloud cover (octa). The coefficients $X, Y, Z, \alpha$ and $\beta$ were obtained as $0.631,0.0382,0.0133,0.19$ and 0.60 for the lowland site and $0.737,0.014,0.0077,0.20$ and 0.59 for the upper mountain site.

Table 2 presents a summary of annual mean, standard deviation and variability of $G, a$ and $R_{\mathrm{ns}}$ at the study sites from 1992 to 1995. As indicated in Table 2, annual mean of $G$ was highest at the lowland site and lowest at the intermediate mountain site. In particular, the former is in line with the observed low annual mean cloud cover (58.8\%) and low precipitation (704 \pm $116 \mathrm{~mm} \mathrm{yr}^{-1}$ ) at the lowland site, while the latter is indicative of the possible combined effects of winter foggy conditions and summer convective cloudiness at the intermediate mountain site, both of which significantly attenuate solar radiation.

Of the annual incoming solar radiation at the study sites, about $22 \%$ was reflected at the lowland site, $26 \%$ at the intermediate mountain site and $36 \%$ at the upper mountain site. Annually, $R_{\mathrm{ns}}$ amounted to $100.5 \mathrm{~W} \mathrm{~m}^{-2}$ at the lowland site, being 1.1 and 1.2 times that of the intermediate and upper mountain sites respectively. During the study period, inter-annual variability of mean $G, R_{\mathrm{ns}}$ and $a$ was less than $9 \%$.

\subsection{Vertical profile of shortwave radiative components on clear sky days}

By averaging radiation data for the study sites according to seasons, $G$ showed a gradient of $1.2 \pm$ $0.35 \mathrm{~W} \mathrm{~m}^{-2} / 100 \mathrm{~m}$ in winter and $-2.5 \pm 0.96 \mathrm{~W} \mathrm{~m}^{-2}$ / $100 \mathrm{~m}$ in summer. The magnitude and signs of these gradients are consistent with the discussion in Section 3.1. Furthermore, the vertical profile of $G, a$ and $R_{\mathrm{ns}}$ on selected clear sky days in winter (29 February 1992) and summer (20 August 1993) in the study area is presented in Fig. 3. Global solar radiation at the upper mountain site exceeded that at the lowland site by $18 \%$ on the winter day and by $11 \%$ on the summer day. Thus, given a clear sky condition at the sites, the vertical profile of $G$ showed a positive gradient. This gradient amounted to $2.22 \mathrm{~W} \mathrm{~m}^{-2} / 100 \mathrm{~m}$ on the clear sky summer day and $2.03 \mathrm{~W} \mathrm{~m}^{-2} / 100 \mathrm{~m}$ on the winter day. In general, during clear sky conditions (with $N=0$ octa), hourly $G$ constituted $76 \%$ of extraterrestrial solar radiation at the upper mountain site and $68.5 \%$ at the lowland site.

Higher $G$ recorded at the mountain sites (relative to the lowland site) during clear sky conditions could be attributed to the effect of reduced air mass, shorter path length and higher atmospheric transparency induced by clean and dry air at high elevations. The altitudinal rise in $G$ observed here for clear sky conditions justifies the rise in solar ultraviolet radiation with elevation reported by some investigators (e.g. Blumthaler et al. 1997, Albold 1999).

Although $G$ increased with elevation on a clear sky winter day (Fig. 3), $R_{\text {ns }}$ showed a negative gradient

Table 2. Annual mean, standard deviation and variability of incoming solar radiation $\left(G ; \mathrm{W} \mathrm{m}^{-2}\right)$, surface albedo (a; \%) and net shortwave radiation $\left(R_{\mathrm{ns}} ; \mathrm{W} \mathrm{m}^{-2}\right)$ at the lowland site $(\mathrm{Br})$, intermediate mountain site $(\mathrm{Ge})$ and upper mountain site (Fe) from

\begin{tabular}{|c|c|c|c|c|c|c|c|}
\hline \multirow{2}{*}{ Variable } & \multirow{2}{*}{ Site } & & & \multicolumn{3}{|l|}{ Year } & \multirow{2}{*}{$\begin{array}{c}\text { Inter-annual } \\
\text { variability (\%) }\end{array}$} \\
\hline & & 1992 & 1993 & 1994 & 1995 & 1992-1995 & \\
\hline \multirow[t]{3}{*}{$G$} & $\mathrm{Br}$ & 132.8 & 130.4 & 124.4 & 129.2 & $129.2 \pm 3.5$ & 2.7 \\
\hline & $\mathrm{Ge}$ & 128.5 & 127.6 & 114.8 & 122.8 & $123.4 \pm 6.2$ & 5.1 \\
\hline & $\mathrm{Fe}$ & 129.4 & 132.0 & - & 122.5 & $128.0 \pm 4.8$ & 3.8 \\
\hline \multirow[t]{3}{*}{$a$} & $\mathrm{Br}$ & 22.0 & 21.6 & 22.1 & 23.2 & $22.2 \pm 0.7$ & 3.2 \\
\hline & $\mathrm{Ge}$ & 25.8 & 25.8 & 25.1 & 26.5 & $25.8 \pm 0.6$ & 2.3 \\
\hline & $\mathrm{Fe}$ & 38.3 & 32.6 & - & 37.1 & $36.0 \pm 3.0$ & 8.3 \\
\hline \multirow[t]{3}{*}{$R_{\mathrm{ns}}$} & $\mathrm{Br}$ & 103.6 & 102.2 & 96.9 & 99.2 & $100.5 \pm 3.0$ & 3.0 \\
\hline & $\mathrm{Ge}$ & 95.3 & 94.7 & 86.0 & 90.3 & $91.6 \pm 4.3$ & 4.7 \\
\hline & $\mathrm{Fe}$ & 79.8 & 89.0 & - & 77.5 & $82.1 \pm 6.1$ & 7.4 \\
\hline
\end{tabular}
1992-1995 

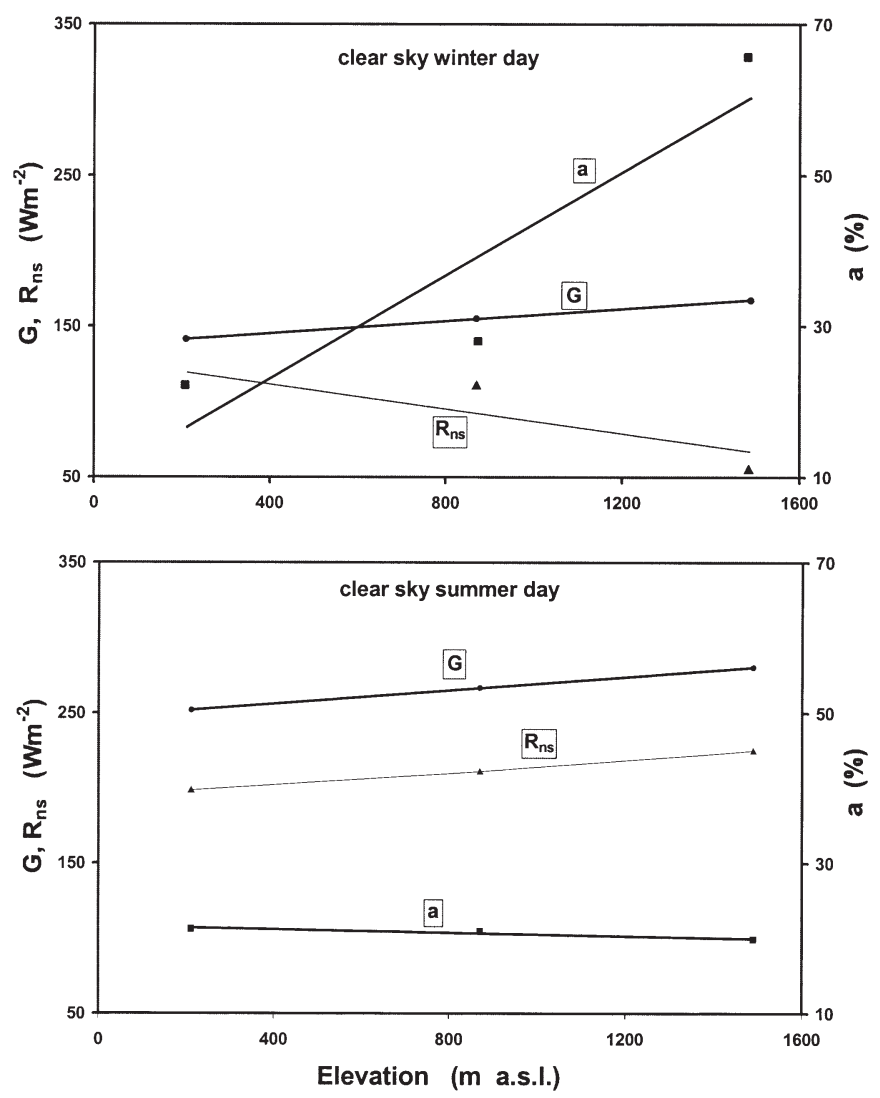

Fig. 3. Vertical profile of incoming solar radiation, $G$, surface albedo, $a$, and net shortwave radiation, $R_{\mathrm{ns}}$ on selected clear sky day in winter (29 February 1992) and summer (20 August 1993)

amounting to $-4.1 \mathrm{~W} \mathrm{~m}^{-2} / 100 \mathrm{~m}$ due to increase in albedo. However, since a was low during summer (mostly ranging between 19 and $24 \%$ for the study sites), $R_{\text {ns }}$ (similar to $G$ ) increased with elevation on a clear sky summer day (with a positive gradient of $2.1 \mathrm{~W}$ $\left.\mathrm{m}^{-2} / 100 \mathrm{~m}\right)$.

During the entire study period (1992-1995) however, $R_{\mathrm{ns}}$ showed a vertical gradient of $-1.54 \mathrm{~W} \mathrm{~m}^{-2} / 100 \mathrm{~m}$ in the study area. Since daytime distribution of the net radiative flux is almost entirely governed by the shortwave radiation regime, net radiant energy at the lowland site (for conversion into soil, sensible and latent heat fluxes) is expected to exceed that at the mountain sites.

\subsection{Estimation of diffuse radiation in the study area}

The focus in this section shall be on the lowland and upper mountain sites for which cloud cover, sunshine duration and solar radiation data were available. In particular, the estimation of $D$ for these sites shall be based on relations proposed by Page (1961) as well as those of the DIN-VDI (German Institute for Standards Association of German Engineers) (1999). Given $N$, $D(N)$ in $\mathrm{W} \mathrm{m}^{-2}$ arriving on a surface can be defined (DIN-VDI 1999) as:

$$
D(N)=G(N)-\left(1-\frac{N}{8}\right) I \sin \gamma
$$

where $I\left(\mathrm{~W} \mathrm{~m}^{-2}\right)$ is that fraction of the extraterrestrial solar radiation impinging on the earth's atmosphere, $\gamma$ is the solar elevation $\left({ }^{\circ}\right)$ and $G(N)$ denotes solar radiation $\left(\mathrm{W} \mathrm{m}^{-2}\right)$ as a function of cloud cover. $G(N)$ has been parameterised by Kasten (1983).

Page (1961) recommended the following equation for estimating the monthly mean of $\bar{D}$

$$
\bar{D} / \bar{G}=1.00-1.13 \bar{K}_{\mathrm{T}}
$$

where the bar represents the monthly mean. While examining the validity of 8 different diffuse relations, Ma \& Iqbal (1984) recommended Page's correlation for estimating monthly mean daily diffuse radiation. Defining the ratio of diffuse to global radiation as the diffuse fraction $K_{\mathrm{d}}$ and applying Eq. (5) to estimate $D$, the relationship between estimated monthly $K_{\mathrm{d}}$ and relative sunshine duration at the lowland site and upper mountain site (based on input data spanning 1991 to 1994) can be expressed as:

$$
K_{\mathrm{d}}=A_{1}-A_{2} \frac{S}{S_{0}}
$$

for which $A_{1}$ and $A_{2}$ amounted to 0.777 and 0.674 for the lowland site and 0.752 and 0.624 for the upper mountain site. The slight difference in the magnitude of the coefficients for the lowland and mountain sites can be attributed to variation in local climatic conditions. Ma \& Iqbal (1984) reported $A_{1}=0.791$ and $A_{2}=$ 0.635 . Furthermore, if the ratio of diffuse solar radiation to extraterrestrial radiation is defined as the diffuse index $K_{\mathrm{i}}$, estimated monthly $K_{\mathrm{i}}$ and $S / S_{0}$ can be related as:

$$
K_{\mathrm{i}}=B_{1}+B_{2}\left(S / S_{0}\right)+B_{3}\left(S / S_{0}\right)^{2}
$$

for which $B_{1}, B_{2}$ and $B_{3}$ amounted to $0.153,0.314$ and -0.366 for the lowland site and $0.172,0.242$ and -0.310 for the upper mountain site.

Following Eq. (4), Fig. 4 presents estimated $D$ averaged for each season (from 12:00 to 14:00 h CET [Central European Time]) as a function of cloud cover at the lowland and mountain sites. The input data spanned 2 yr (1991-1992) for the lowland site and 4 yr (19911994) for the upper mountain site. Meteorological seasons are implied here (i.e. spring: March-May; summer: June-August; autumn: September-November; and winter: December-February). $D$ slowly increased with $N$ to a maximum of about 5 octa at the study sites, after which it fell. Estimated high values of 

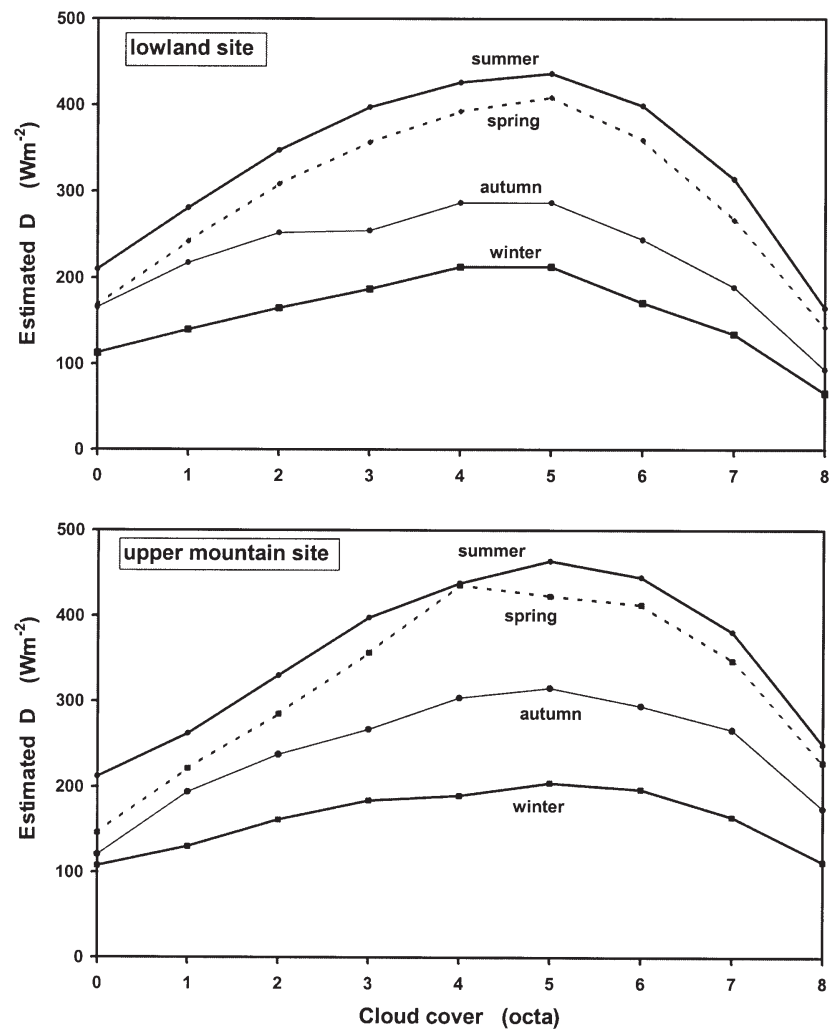

Fig. 4. Estimated diffuse sky radiation, $D$, averaged for each season (from 12:00 to 14:00 h CET) as a function of cloud cover at the lowland and upper mountain sites

$D$ (particularly up to 5 octa) at the sites could be attributed to enhanced forward scattering and reflection from the side of clouds. The decline in $D$ with $N>5$ octa can be linked with pronounced attenuation of $G$ arising from increased cloudiness.

Fig. 5 presents estimated $K_{\mathrm{d}}$ averaged for each season (from 12:00 to 14:00 h CET) as a function of cloud cover at the lowland and upper mountain sites. $K_{\mathrm{d}}$ increased steadily with $N$. With clear sky conditions, at the lowland site, the lowest $K_{\mathrm{d}}$ amounted to 0.25 , while the highest amounted to 0.33 . Corresponding values at the upper mountain site amounted to 0.22 and 0.34 respectively.

Estimated monthly $K_{\mathrm{d}}$ at the lowland and mountain sites is presented in Fig. 6. In contrast to G (see Fig. 1), $K_{\mathrm{d}}$ was higher at the mountain site (relative to the lowland site) from April to October, when Mie forward scattering of incoming radiation by convective clouds prevailed at this high-elevation site. From November to February, higher estimated monthly $K_{\mathrm{d}}$ at the lowland site (relative to the mountain site) is mainly due to increased atmospheric turbidity. In view of the low $K_{\mathrm{d}}$ at the lowland site in summer (particularly in August, with $K_{\mathrm{d}}=0.58$ ), solar energy devices (e.g. solar concentrators, solar heaters, solar dryers) would have high performance during these months at this site. Errors associated with these estimates of $D$ and $K_{\mathrm{d}}$ are expected to be in the range of $\pm 6 \%$ for the lowland site and $\pm 9 \%$ for the upper mountain site.

\section{CONCLUDING REMARKS}

This study examines the shortwave radiation budget at 3 locations in south-west Germany, whose elevations ranged from 212 to $1489 \mathrm{~m}$ a.s.l. Relative to the mountain sites (where the shortwave radiation budget is strongly influenced by summer convective clouds, a low summer atmospheric clearness index and winter snowy conditions), the lowland study site recorded greater net shortwave radiation. During the study period, the ratio of mean net to incoming shortwave radiation was $78 \%$ at the lowland site, while only 74 and $64 \%$ at the intermediate and upper mountain sites respectively. This has a number of implications:

- For instance, the variability of $G$ lends insight into the distribution of other components of shortwave radiation, including photosynthetically active radiation and UV radiation (Feister \& Grasnick 1992, Albold 1999, Udo \& Aro 1999).
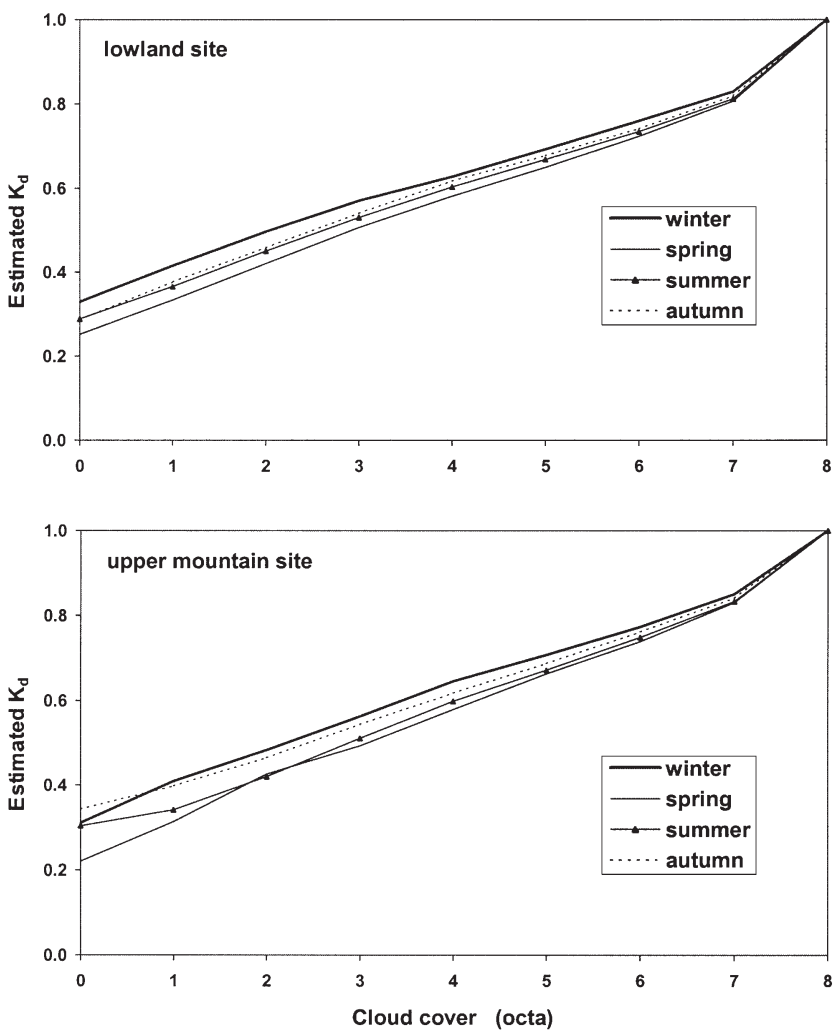

Fig. 5. Estimated diffuse fraction, $K_{\mathrm{d}}$, averaged for each season (from 12:00 to 14:00 h CET) as a function of cloud cover at the lowland and upper mountain sites 


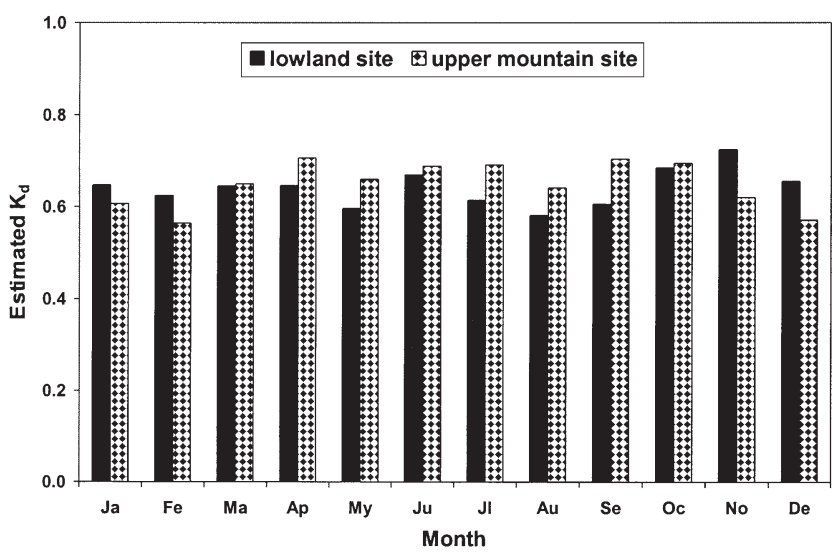

Fig. 6. Annual variation of estimated diffuse fraction, $K_{\mathrm{d}}$ at the lowland and upper mountain sites

- Although the atmospheric clearness index over mountains exceeds that over lowland during clear sky conditions, the frequency of convective clouds at the former renders the lowland site a better option for solar-energy applications, particularly in summer.

- Since daytime distribution of the net radiative flux is almost entirely governed by the shortwave radiation regime, it follows that on annual average, net radiant energy available at the lowland site (for conversion into soil, sensible and latent heat fluxes) exceeds that at the mountain sites.

Diffuse sky radiation has been estimated for the lowland and upper mountain sites using the equations proposed by Page (1961) and DIN-VDI (1999). Estimated diffuse solar radiation increased with cloud amount only to a maximum of about 5 octa. Sky and turbidity conditions at the study sites can be inferred from the estimated diffuse fraction.

Acknowledgements. This study was conducted within the framework of a regional climate project (REKLIP) funded by the Ministry of Science and Research, Baden-Wuerttemberg, Germany. Thanks are due to the funding agency as well as to Prof. em. A. Kessler, Prof. Dr. L. Jaeger and Mr. W. Wicke for their participation in REKLIP on behalf of the Meteorological Institute, University of Freiburg, Germany.

\section{LITERATURE CITED}

Albold A (1999) Untersuchungen zum ultravioletten Strahlungstransfer im alpinen Gelände. Schriftenreihe des Fraunhofer Instituts, München, Atmosphärische Umweltforschung, Band 61

Barry RG (1992) Mountain weather and climate. Methuen, New York

Editorial responsibility: Hans von Storch,

Geesthacht, Germany
Blumthaler M, Webb AR, Seckmeyer G, Bais AF, Huber M, Mayer B (1997) Simultaneous spectroradiometry: a study of solar UV irradiance at two altitudes. Geophys Res Lett 21:2805-2808

DIN-VDI (1999) Environmental meteorology, Meteorological measurements, Part 2-Global radiation, turbidity, visual weather observations, meteorological measuring stations for agric purposes. Handbook 333, Beuth Verlag, Berlin

Feister U, Grasnick KH (1992) Solar UV radiation measurements at Potsdam $\left(52^{\circ} \mathrm{N}, 13^{\circ} \mathrm{E}\right)$. Solar Energy 49:541-548

Friis-Christensen E (2000) Sun, cloud and climate. Clim Change 47:1-5

Garratt JR (1994) Incoming shortwave fluxes at the surfacea comparison of GCM results observations. J Clim 7:72-80

Hammonds M (2000) Solar photovoltaics. Renewable Energy Focus July/August 2000:28-29

Ianetz A, Lyubansky V, Setter I, Evseev EG, Kudish AI (2000) A method for chararcterization of sites with regard to solar energy utilization by statistical analysis of their solar radiation data as performed for three sites in the Isreal Negev Region. Solar Energy 69:283-293

Iziomon MG (2000) Characteristic variability, vertical profile and modelling of surface radiation budget in the southern Upper Rhine valley region. Ber Meteorol Inst Univ Freiburg 4

Iziomon MG, Aro TO (1998) The diffuse fraction of global solar irradiance at a tropical location. Theor Appl Climatol 61:77-84

Kalthoff N, Fiedler F, Kohler M, Kolle O, Mayer H, Wenzel A (1999) Analysis of energy balance components as a function of orography and land use and comparison of results with the distribution of variables influencing local climate. Theor Appl Climatol 62:65-84

Kasten F (1983) Parametriserung der Globalstrahlung durch Bedeckungsgrad und Trübungs-faktor. Ann Meteorol NF 20:49-50

Liu DL, Scott BJ (2001) Estimation of solar radiation in Australia from rainfall and temperature observations. Agric For Meteorol 106:41-59

Ma CCY, Iqbal M (1984) Statistical comparison of solar radiation correlations. Solar Energy 33:143-148

Page JK (1961) The estimation of monthly mean values of daily total of shortwave radiation on vertical and inclined surfaces from sunshine records for latitudes $40^{\circ} \mathrm{N}-40^{\circ} \mathrm{S}$. Proc UN Conf New Sources Energy Pap No. S98 (4): 378-390

REKLIP (1995) REKLIP Klima Atlas Oberrhein Mitte-Süd, Text Volume. Verlagsgemeinschaft IFG-Coprur-vdf (IFG), Offenbach

Thornton PE, Running SW (1999) An improved algorithm for estimating incident daily solar radiation from measurements of temperature, humidity, and precipitation. Agric For Meteorol 93:211-228

Thornton PE, Hasenauer H, White MA (2000) Simultaneous estimation of daily solar radiation and humidity from observed temperature and precipitation: an application over complex terrain in Austria. Agric For Meteorol 104: 255-271

Udo SO, Aro TO (1999) Global PAR related to global solar radiation for central Nigeria. Agric For Meteorol 97: 21-31

Wild M, Ohmura A, Gilgen H, Roeckner E (1995) Validation of general circulation model radiative fluxes using surface observations. J Clim 8:1309-1324

Submitted: November 30, 2000; Accepted: July 31, 2001

Proofs received from author(s): February 25, 2002 